\title{
Proton pump inhibitor failure in gastro-oesophageal reflux disease: a perspective aided by the Gartner hype cycle
}

\author{
Author: Robert C Heading ${ }^{\mathrm{A}}$
}

\begin{abstract}
Some patients with gastro-oesophageal reflux disease (GORD) experience symptoms despite proton pump inhibitor (PPI) treatment. In the early years of their availability, these drugs were thought to be a highly effective treatment for GORD and realisation that symptom relief was often incomplete came as a disappointment. This review considers the evolution of thinking with the aid of the Gartner hype cycle - a graphical depiction of the process of innovation, evolution and adoption of new technologies. Acknowledging that over-simplistic concepts of GORD have been largely responsible for inflated expectations of PPI therapy is an important step forward in establishing how patients with persistent symptoms, despite PPIs, should be assessed and treated.
\end{abstract}

KEYWORDS: Gastro-oseophageal reflux, GORD, proton pump inhibitors, reflux symptoms

\section{Introduction}

During the last 10 years, a succession of publications has told us that symptoms in many patients with gastro-oesophageal reflux disease (GORD) are inadequately controlled by proton pump inhibitors (PPIs). Various terms have been used to describe the problem - persistent symptoms or refractory symptoms on PPI, partial, inadequate or non-response to PPI and just 'PPI failure' in GORD - but the message is the same, namely that the symptom suppression desired by patient and physician is often not attained. Today's recognition of this state of affairs is worth examining in the context of the earlier consensus to the effect that PPIs provided highly effective therapy for GORD. Specifically, it is interesting to consider this with the aid of the Gartner hype cycle (Gartner Inc, Stamford, Connecticut, USA), the five-stage sequence proposed by the American information technology company to illustrate the development, adoption, refinement and use of novel technologies (Fig 1). ${ }^{1}$ More than 50 years ago, Laurence outlined a similar concept to show how attitudes to newly introduced medicines often change with time ${ }^{2}$ and it is useful

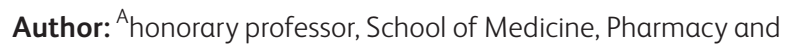
Health, Durham University, Durham, UK

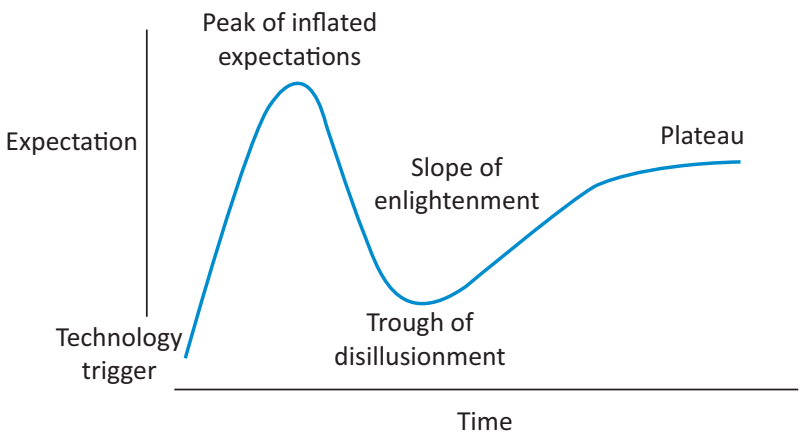

Fig 1. The Gartner hype cycle.

to review the history of PPIs with reference to the 'hype' that may follow many types of innovation.

\section{Phase 1 - the technology trigger}

The era of medication specifically targeting gastric acid production began with the first histamine $\mathrm{H} 2$ antagonist in the 1960s. The expectation that these drugs would be effective treatments for peptic ulcer disease and GORD proved justified. Development of the PPIs followed. Their greater potency in suppressing gastric acid secretion suggested even better outcomes in treating acid-peptic diseases could be anticipated.

\section{Phase 2 - the peak of inflated expectations}

Efficacy of the PPIs in reflux disease was established in clinical trials that focused on healing oesophagitis and suppressing heartburn. Recruitment to these trials often required that both oesophagitis and heartburn were present pre-treatment, enabling the best possible 'clean' population of patients to be studied. If efficacy of the medication was established, licensing would follow so long as adverse reactions were minimal. In due course, four PPIs meeting the criteria became available - omeprazole, lansoprazole, pantoprazole and rabeprazole. Esomeprazole followed a little later. By the late 1990s, the accepted view of the efficacy of the PPIs in GORD was well documented in a metaanalysis of more than 40 papers, ${ }^{3}$ which reported healing of oesophagitis in $84 \%$ of patients after 12 weeks of treatment and attainment of complete heartburn relief, as illustrated in Fig 2. 


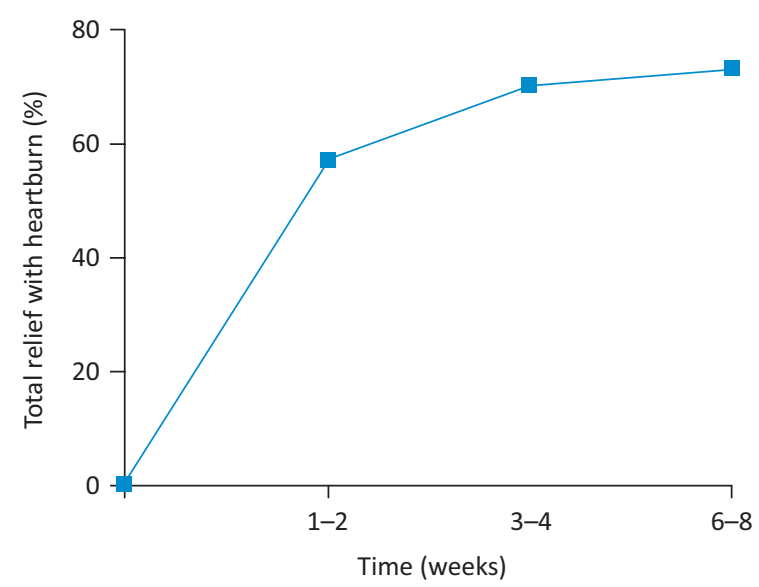

Fig 2. The proportion of patients with endoscopic oesophagitis gaining relief of heartburn after starting on a proton pump inhibitor. Adapted from Chiba et al. ${ }^{3}$

However good the data about efficacy, acceptance of any drug by physicians is reinforced when its mechanism of action is credible in terms of physiology and pharmacology. By the late 1990s, there was acknowledgement that heartburn and oesophagitis come about as a result of increased exposure of the oesophageal mucosa to acidic gastric content, consequent upon failure of the lower oesophageal sphincter and impaired oesophageal body motility. The disorder is not one of gastric hypersecretion but it may nevertheless be expected that drugs reducing gastric acidity would relieve heartburn and heal oesophagitis. Studies of 24-hour intragastric acidity indeed confirmed a sustained reduction after PPI administration, ${ }^{4}$ providing a sound rationale for the efficacy shown in the clinical trials (Fig 3).

\section{Phase 3 - the trough of disillusionment}

After the turn of the millennium, publications began to appear suggesting that symptom suppression was not as good as presented in earlier reports. Night-time heartburn was among the first problems reported, with only $50 \%$ of patients taking medication being fully satisfied with the symptom control achieved. ${ }^{5}$ Further reports followed, with a systematic review published in $2010^{6}$ concluding that in observational studies from primary care, $45 \%$ (30-60\%) of GORD patients on PPIs experienced persistent reflux symptoms, often with reduced wellbeing as a consequence. However, these figures may not be quite as bad as they seem. Not all patients take their PPIs daily as prescribed ${ }^{7,8}$ and those who choose to miss one or more days knowing that symptoms will recur will be recorded as having persistent symptoms. These patients are of course simply exercising a choice that is theirs to make.

Several reasons help to explain the growing realisation that PPI treatment of reflux disease was not always successful. First, the classic symptoms of reflux disease are heartburn and regurgitation, but the latter responds less well than the former to medication. In fact, the therapeutic gain achieved by a PPI with respect to regurgitation (ie the magnitude of improvement over the placebo response) is only about $17 \% .{ }^{9}$ Enquiring about improvement in reflux symptoms will therefore generate a less favourable result than asking about heartburn alone, as was done in most early clinical trials.

Second, symptom evaluation in GORD patients participating in clinical trials changed during the decade 2000-10, with symptoms being more often evaluated using questionnaires completed by patients themselves rather than symptom assessments being undertaken by physicians. More comprehensive and systematic symptom assessments were adopted, with the creation and validation of questionnaires such as the Reflux Disease Questionnaire. ${ }^{10}$ This enquires about dyspepsia (upper abdominal pain/discomfort) besides heartburn and regurgitation and evaluates all three in terms of the severity and frequency of symptoms, not just their presence or absence. Some other questionnaires are more comprehensive still. Dyspepsia, throat symptoms (sore throat, hoarseness, throat clearing, cough) and irritable bowel syndrome all occur more commonly in patients with GORD than would be predicted by chance ${ }^{11-14}$ and failure of these symptoms to respond to a PPI obviously constitutes an ongoing symptom burden for the patient.

Third, it gradually became accepted that non-erosive reflux disease (NERD) is actually more common than erosive disease (ie oesophagitis) and responds less well to PPIs. ${ }^{15}$

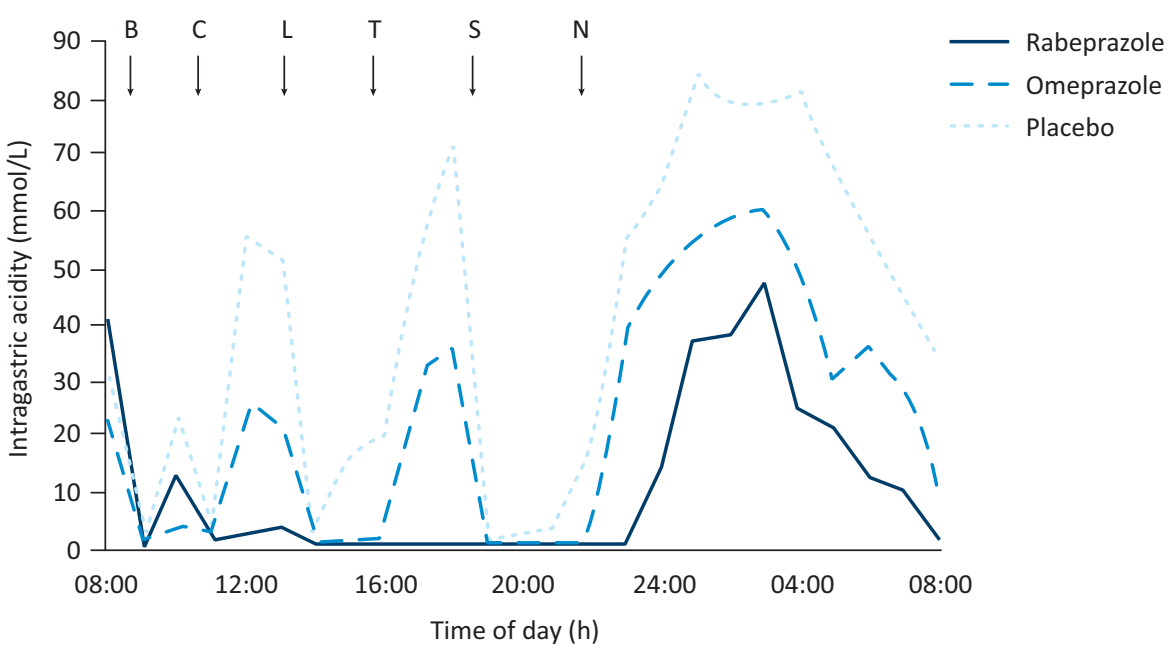

Fig 3. Median intragastric acidity following a single dose of rabeprazole, omeprazole or placebo in 23 healthy subjects. $B=$ breakfast; $C=$ coffee; $L=$ lunch; $\mathrm{T}$ = tea; $\mathrm{S}=$ supper; $\mathrm{N}=$ night-time snack. Reproduced with permission from Williams et al. ${ }^{4}$ 
Coincident with the realisation that GORD patients were not consistently 'cured' by PPI treatment, two long-held physiological concepts of reflux disease were found wanting. One of these is indirectly illustrated in Fig 3, where the 24-hour record of intragastric acidity after placebo shows a substantial reduction in acidity after meals. The gastric acid has been buffered by ingested food. Why is it, therefore, that heartburn tends to be most frequent after meals - the very time when intragastric acidity has been reduced? The basis of the apparent anomaly was revealed by Fletcher et al, ${ }^{16}$ who performed dual (intragastric and intraoesophageal) $\mathrm{pH}$ recording and observed that reflux episodes recorded in the oesophagus after a meal were of a lower $\mathrm{pH}$ than the $\mathrm{pH}$ simultaneously recorded in the stomach. Their further work then showed that a layer of acid begins to accumulate on top of the gastric contents about 15 minutes after taking a meal and that this reservoir, which they called the 'acid pocket', is the source of reflux into the oesophagus during the postprandial period. During this time, therefore, acidity in the body of the stomach has little significance for gastro-oesophageal reflux. The numerous studies of intragastric acidity undertaken in previous years are consequently of diminished relevance.

The second concept found to be flawed was the direct attribution of heartburn to acid reflux into the oesophagus. Although acid gastro-oesophageal reflux does indeed cause heartburn, the use of intraoesophageal $\mathrm{pH}$ and impedance measurement in patients with persistent reflux symptoms while on PPIs demonstrated that although some episodes of heartburn were associated with the occurrence of acid gastro-oesophageal reflux, others coincided with reflux of fluid with a $\mathrm{pH}$ above 4 (weakly acidic reflux) and some were not associated with any demonstrable gastro-oesophageal reflux at all. ${ }^{17}$ Thus, heartburn is not solely caused by acid reflux and, in consequence, suppression of acid will not always abolish the heartburn. More problems for the PPIs began to appear with reports of adverse reactions. The sporadic occurrence of diarrhoea and enhanced susceptibility to enteric infections had been known for several years, but one by one a catalogue of other unwanted consequences was spelled out: pneumonia, iron, vitamin B12 and calcium deficiencies, fractures, interstitial nephritis, microscopic colitis, hypomagnesaemia, enterochromaffinlike cell hyperplasia and drug-drug interactions. ${ }^{18-20}$ Then, as if all of this were not enough to paint a black picture of PPIs, unequivocal evidence emerged that administering the drug for a period of 4 weeks not only provokes rebound gastric secretion when the medication is stopped ${ }^{21}$ but also provokes the appearance of upper gastrointestinal symptoms, even in individuals who had no such symptoms previously. ${ }^{22}$ This observation undermines the suggestion that PPI treatment given to patients with a presumptive diagnosis of GORD should be stopped after some weeks 'to see if the symptoms recur'. Symptom recurrence in such circumstances cannot to be interpreted as confirmation of the original diagnosis.

Some of the adverse consequences of PPI treatment detailed above are open to question, however. Epidemiological studies linking PPI administration with purported adverse consequences often have difficulty in correcting for confounding factors, of which the likelihood of GORD patients being overweight and the fact that PPI treatment tends to be given to people with various acute illnesses are just two.
Moayyedi ${ }^{23}$ has suggested that a drive to allege the existence of adverse cause and effect relationships has led to a loss of the scientific rigour shown by the pioneers of clinical epidemiology - Richard Doll and Austin Hill, for example - and regrettably this loss leaves today's clinicians with much uncertainty about what the risks of PPIs really are.

It is perhaps unsurprising that the later stages of the 'trough of disillusionment' may be marked by negative information exaggerating problems or even inventing some where none exist. Therefore, we can consider the possibility that the clinical community is now moving into the next stage of the Gartner hype cycle.

\section{Phase 4 - the slope of enlightenment}

First steps towards enlightenment come from better understanding of the genesis of reflux symptoms. As described earlier, heartburn may be produced by reflux of acidic, weakly acidic and occasionally even non-acidic fluid from the stomach to the oesophagus, but there is obviously a sensory process involved in the perception of the symptom. A normal magnitude and pattern of gastro-oesophageal reflux can be symptomatic ${ }^{24,25}$ while, conversely, $36 \%$ of individuals with reflux sufficiently severe to cause oesophagitis may have no symptoms at all. ${ }^{26}$ Thus, modulation of the sensory processes triggered by gastro-oesophageal reflux may enhance or diminish symptom perception. The afferent limb of autonomic reflexes may likewise be modulated; reflexes activated by intraoesophageal acid may cause airway constriction ${ }^{27}$ and may precipitate episodes of cardiac arrhythmia in individuals with a pre-existing liability to arrhythmia. ${ }^{28}$ Once the modulation of sensory processes activated by gastro-oesophageal reflux episodes is appreciated, the potential occurrence of dyspeptic (upper abdominal) symptoms, asthma, throat symptoms and irritable bowel syndrome in association with gastro-oesophageal reflux becomes understandable. It is important to emphasise - the occurrence of symptoms does not require an abnormal magnitude or pattern of gastro-oesophageal reflux although it is more likely if reflux is abnormally increased. Heightened sensitivity in the oesophagus may in fact be part of a more generalised abnormality with enhanced sensitivity being evident in other parts of the gastrointestinal tract also. ${ }^{29}$ Finally, to complicate things further, there are patients who experience heartburn in the absence of any demonstrable reflux at all. This entity, termed functional heartburn, is thought to occur as a result of altered oesophageal and/or central sensory processes. ${ }^{30,31}$

As with many somatic sensations, the psyche modulates perceived visceral sensation also. Anxiety worsens reflux symptom perception and impairs improvement on therapy. Interestingly, depression has little effect. ${ }^{32,33}$

Acceptance of the existence of heightened (or reduced) visceral sensitivity as a factor determining the symptoms experienced by patients, together with recognition that acid reflux is not the only cause of heartburn, allows the clinician to understand that attempts to treat persistent reflux symptoms simply by pursuing more and more acid suppression are illogical and likely to fail. However, increasing acid suppression is sometimes appropriate. Heartburn that is especially troublesome in the late evening, for example, may well warrant a second dose of a PPI taken before the evening meal although 
different therapeutic approaches currently being appraised may prove helpful too. For example, although PPIs reduce the volume and elevate the $\mathrm{pH}$ of the acid pocket, ${ }^{34}$ the pocket can also be reduced and/or displaced distally away from the gastrooesophageal junction by a prokinetic ${ }^{35}$ and by an alginate, ${ }^{36}$

Such medications offer the prospect of effective add-on therapy to PPIs in patients who continue to suffer symptoms, especially if there is weak acid reflux that will be unaffected by additional acid suppression. To date, however, no medication that directly addresses or modifies increased visceral sensitivity has been identified as a potential treatment for reflux symptoms. This is perhaps an appropriate focus for early research.

For physicians in the UK, well-founded clinical guidelines addressing the problem of 'PPI failure' are conspicuously lacking. In 2014, the National Institute for Health and Care Excellence (NICE) advised primary care practitioners that patients with PPI 'non-responsive' symptoms should be referred for specialist assessment. ${ }^{37}$ Plausible, perhaps, not least because the pragmatic approach of simply increasing the PPI to twice daily administration - to see what happens - has never been tested in a controlled trial and the magnitude of the placebo response is unknown. Moreover, recent evidence suggests that persistent symptoms in most patients taking PPIs are not due to reflux, with no difference in this respect between those taking the medication once daily and twice daily. ${ }^{38}$ Clinicians therefore have to recognise that a GORD diagnosis in these patients may be incorrect, notwithstanding credible symptoms, so specialist assessment may well be appropriate.

To date, NICE has not offered guidance for the specialist who sees these patients. It is not appropriate here to review the use and interpretation of $\mathrm{pH}$ and impedance testing, but comprehensive assessment of patients with persistent reflux symptoms while on a PPI will often require this technology. Not always, however. Persistent heartburn and regurgitation despite PPI therapy may occur in association with a large, fixed hiatus hernia identifiable by X-ray or endoscopy.

\section{Conclusion}

When the PPIs first became widely available, many GORD patients had their symptoms well controlled by treatment. This remains true today. Nevertheless, with hindsight it is obvious that our understanding of GORD 20 years ago was naive in many respects. In particular, the belief that PPI treatment would be a cure-all for GORD symptoms - 'inflated expectations' was mistaken and the subsequent disappointment - the 'trough of disillusionment' - was also correspondingly overdone. A tendency to blame someone or something else when our expectations are not fulfilled is an unattractive aspect of human behaviour and, in the context of GORD treatment, the inference that it is the drug that is at fault - 'PPI failure in GORD' - is a less than honest acknowledgment of our own inadequacies. The truth is that our understanding of gastro-oesophageal reflux disease has been over-simplistic and, in some respects, incorrect; the problem has been our failure, not a failure of PPIs.

The key elements of recent progress are

> acknowledgement that GORD symptom suppression is often incomplete

> a better grasp of the pathophysiology of symptom causation, especially the importance of modulation of visceral sensation

Table 1. The basis of over-expectation, subsequent disillusion and enlightenment in the use of PPIs for GORD

\section{The genesis of expectations}

Clinical trials show PPIs produce excellent oesophagitis healing and good heartburn relief

They are potent
suppressors
of gastric acid
secretion

Adverse reactions
are infrequent are infrequent GORD = gastro-oesophageal reflux disease; IBS = irritable bowel syndrome; NERD = non-erosive reflux disease; $P$ PI = proton pump inhibitor

$>$ a fuller understanding of the complexity of symptoms occurring in most patients with GORD

$>$ critical judgement of what may reasonably be expected of the PPIs, including a measure of doubt about some of the alleged adverse reactions.

If early over-optimism for the PPIs in GORD was followed by excessive pessimism (Table 1), there is good reason to believe we are now well into climbing the 'slope of enlightenment'.

\section{Conflicts of interest}

In the past RCH has served on advisory boards for pharmaceutical companies - Takeda, AstraZeneca and Reckitt Benckiser in the period 2010-14. However, he has no such roles at present. 


\section{References}

1 Fenn J, Raskino M. Mastering the hype cycle. Brighton, MA: Harvard Business Press, 2008.

2 Laurence DR, Moulton R. Clinical pharmacology. Boston, MA: Little, Brown and Co, 1960.

3 Chiba N, De Gara CJ, Wilkinson JM, Hunt RH. Speed of healing and symptom relief in grade II to IV gastroesophageal reflux disease: a meta-analysis. Gastroenterology 1997;112:1798-810.

4 Williams MP, Sercombe J, Hamilton MI, Pounder RE. A placebocontrolled trial to assess the effects of 8 days of dosing with rabeprazole versus omeprazole on 24 -h intragastric acidity and plasma gastrin concentrations in young healthy male subjects. Aliment Pharmacol Therap 1998;12:1079-89.

5 Shaker R, Castell DO, Schoenfeld PS, Spechler SJ. Nighttime heartburn is an under-appreciated clinical problem that impacts sleep and daytime function: the results of a Gallup survey conducted on behalf of the American Gastroenterological Association. Am J Gastroenterol 2003:98;1487-93.

6 El-Serag H, Becher A, Jones R. Systematic review: persistent reflux symptoms on proton pump inhibitor therapy in primary care and community studies. Aliment Pharmacol Ther 2010;32:720-37.

7 Van Soest EM, Sturkenboom MC, Dieleman JP, Sturkenboom MC, Kuipers EJ. Persistence and adherence to proton pump inhibitors in daily clinical practice. Aliment Pharmacol Ther 2006;24:377-85.

8 Hungin AP, Hill C, Molloy-Bland M, Raghunath A. Systematic review: patterns of proton pump inhibitor use and adherence in gastroesophageal reflux disease. Clin Gastroenterol Hepatol 2012;10:109-16.

9 Kahrilas PJ, Howden CW, Hughes N. Response of regurgitation to proton pump inhibitor therapy in clinical trials of gastroesophageal reflux disease. Am J Gastroenterol 2011;106:1419-25.

10 Shaw MJ, Talley NJ, Beebe TJ et al. Initial validation of a diagnostic questionnaire for gastroesophageal reflux disease. Am J Gastroenterol 2001;96:52-7.

11 Gerson LB, Kahrilas PJ, Fass R. Insights into gastroesophageal reflux disease-associated dyspeptic symptoms. Clin Gastroenterol Hepatol 2011;9:824-33.

12 Bruley des Varannes S, Marek L, Humeau B, Lecasble M, Colin R. Gastroesophageal reflux disease in primary care. Prevalence, epidemiology and quality of life of patients. Gastroenterol Clin Biol 2006;30:364-70.

13 Gasiorowska A, Poh CH, Fass R. Gastroesophageal reflux disease (GERD) and irritable bowel syndrome (IBS) - is It one disease or an overlap of two disorders? Dig Dis Sci 2009;54:1829-34.

14 Jung HK, Halder S, McNally M et al. Overlap of gastro-oesophageal reflux disease and irritable bowel syndrome: prevalence and risk factors in the general population. Aliment Pharmacol Therap 2007;26:453-61.

15 Modlin IM, Hunt RH, Malfertheiner P et al. Diagnosis and management of non-erosive reflux disease - the Vevey NERD consensus group. Digestion 2009;80:74-88.

16 Fletcher J, Wirz A, Young J, Vallance R, McColl KE. Unbuffered highly acidic gastric juice exists at the gastro-oesophageal junction after a meal. Gastroenterology 2001;121:776-83.

17 Zerbib F, Roman S, Ropert A et al. Esophageal pH-impedance monitoring and symptom analysis in GERD: a study in patients off and on therapy. Am J Gastroenterol 2006;101:1956-63.

18 Yang YX, Metz DC. Safety of proton pump inhibitor exposure. Gastroenterology 2010;139:1115-27.

19 Sheen E, Triadafilopoulos G. Adverse effects of long-term proton pump inhibitor therapy. Dig Dis Sci 2011;56:931-50.

20 Ogawa R, Echizen H. Drug-drug interaction profiles of proton pump inhibitors. Clin Pharmacokinet 2010;49:509-33.

21 Gillen D, Wirz AA, Ardill JE, McColl KE. Rebound hypersecretion after omeprazole and its relation to on-treatment acid suppression and Helicobacter pylori status. Gastroenterlogy 1999;116:239-47.
22 Reimer C, Søndergaard B, Hilsted L, Bytzer P. Proton-pump inhibitor therapy induces acid-related symptoms in healthy volunteers after withdrawal of therapy. Gastroenterology 2009:137;80-7.

23 Moayyedi P. Making sense of the adverse effects of PPIs. Bethesday, MD: AGA Perspectives, 2016. http://agaperspectives.gastro.org/ making-sense-adverse-effects-ppis/\#.V-TshlsrI-U [Accessed 26 January 2017].

24 Howard PJ, Maher L, Pryde A, Heading RC. Symptomatic gastrooesophageal reflux, abnormal oesophageal acid exposure, and mucosal acid sensitivity are three separate, though related, aspects of gastro-oesophageal reflux disease. Gut 1991;32:128-32.

25 Shi G, Bruley des Varannes S, Scarpignato C, Le Rhun M, Galmiche JP Reflux related symptoms in patients with normal oesophageal exposure to acid. Gut 1995;37:457-64.

26 Ronkainen J, Aro P, Storskrubb T et al. High prevalence of gastroesophageal reflux symptoms and esophagitis with and without symptoms in the general adult Swedish population: a Kalixanda study report. Scand J Gastroenterol 2005;40:275-85.

27 Amarasiri DL, Pathmeswaran A, de Silva HJ, Ranasinha CD. Response of the airways and autonomic nervous system to acid perfusion of the esophagus in patients with asthma: a laboratory study. BMC Pulm Med 2013;13:33.

28 Cuomo R, De Giorgi F, Adinolfi L et al. Oesophageal acid exposure and altered neurocardiac function in patients with GERD and idiopathic cardiac dysrhythmias. Aliment Pharmacol Therap 2006;24:361-70.

29 Trimble KC, Farouk R, Pryde A et al. Heightened visceral sensation in functional gastrointestinal disease is not site-specific. Evidence for a generalized disorder of gut sensitivity. Dig Dis Sci 1995;40:1607-13.

30 Fass R, Tougas G. Functional heartburn: the stimulus, the pain and the brain. Gut 2002;51:885-92.

31 Aziz Q, Fass R, Gyawali P et al. Functional esophageal disorders. Gastroenterology 2016:150:1368-79.

32 Heading RC, Monnikes H, Tholen A, Schmitt H. Prediction of response to $\mathrm{PPI}$ therapy and factors influencing treatment outcome in patients with GORD: a prospective pragmatic trial using pantoprazole. BMC Gastroenterol 2011;11:52.

33 Kessing BF, Bredenoord AJ, Saleh CM, Smout AJ. Effects of anxiety and depression in patients with gastroesophageal reflux disease. Clin Gastroenterol Hepatol 2015;13:1089-95.

34 Rohof WO, Bennink RJ, Boeckxstaens GE. Proton pump inhibitors reduce the size and acidity of the acid pocket in the stomach. Clin Gastroenterol Hepatol 2014;12:1101-7.

35 Rohof WO, Bennink RJ, de Ruigh AA et al. Effect of azithromycin on acid reflux, hiatus hernia and proximal acid pocket in the postprandial period. Gut 2012;61:1670-7.

36 Kwiatek MA, Roman S, Fareeduddin A, Pandolfino JE, Kahrilas PJ. An alginate-antacid formulation (Gaviscon Double Action Liquid) can eliminate or displace the postprandial 'acid pocket' in symptomatic GERD patients. Aliment Pharmacol Ther 2011;34:59-66.

37 National Institute for Health and Care Excellence. Gastrooesophageal reflux disease and dyspepsia in adults: investigation and management. NICE clinical guideline No 184. London: NICE, 2014.

38 Roman S, Keefer L, Imam H et al. Majority of symptoms in esophageal reflux PPI non-responders are not related to reflux. Neurogastroenterol Motil 2015;27:1667-74.

Address for correspondence: Professor RC Heading, School of Medicine, Pharmacy and Health, Durham University, Queens Campus, Stockton on Tees TS17 6BH, UK. Email: rheading@dialstart.net 